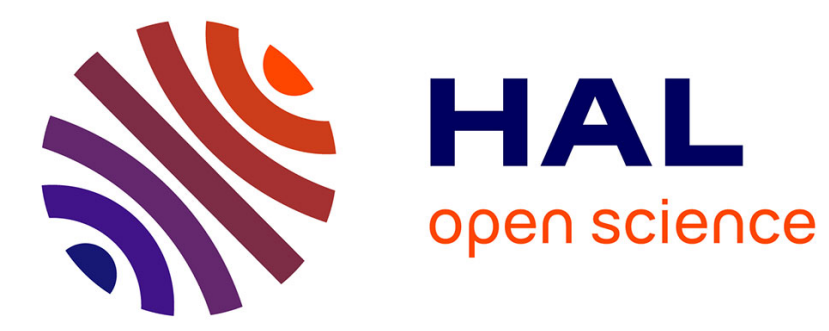

\title{
Prevalence and Treatment of Familial Hypercholesterolemia in France
}

Emilie Bérard, Vanina Bongard, Bernadette Haas, Jean Dallongeville, Marie Moitry, Dominique Cottel, Jean-Bernard Ruidavets, Jean Ferrières

\section{- To cite this version:}

Emilie Bérard, Vanina Bongard, Bernadette Haas, Jean Dallongeville, Marie Moitry, et al.. Prevalence and Treatment of Familial Hypercholesterolemia in France. Canadian Journal of Cardiology, 2019, 35, pp.744 - 752. 10.1016/j.cjca.2019.02.013 . hal-03484972

\section{HAL Id: hal-03484972 \\ https://hal.science/hal-03484972}

Submitted on 20 Dec 2021

HAL is a multi-disciplinary open access archive for the deposit and dissemination of scientific research documents, whether they are published or not. The documents may come from teaching and research institutions in France or abroad, or from public or private research centers.
L'archive ouverte pluridisciplinaire HAL, est destinée au dépôt et à la diffusion de documents scientifiques de niveau recherche, publiés ou non, émanant des établissements d'enseignement et de recherche français ou étrangers, des laboratoires publics ou privés.

\section{다)(1) $(5$}

Distributed under a Creative Commons Attribution - NonCommerciall 4.0 International 


\section{Prevalence and Treatment of familial hypercholesterolemia in France}

Emilie Bérard, MD, PhD, Vanina Bongard, MD, PhD, Bernadette Haas, MD, PhD, Jean

Dallongeville, MD, PhD, Marie Moitry, MD, Dominique Cottel, MD, PhD, Jean-Bernard

Ruidavets, MD, Jean Ferrières, MD, PhD*

Department of Epidemiology, Health Economics and Public Health, UMRIO27 INSERM-

Toulouse University, Toulouse University Hospital, Toulouse, France (Dr Bérard, Prof. Bongard, Dr Ruidavets, Prof. Ferrières); Department of Public Health, Strasbourg University Hospital, Strasbourg, France (Dr Haas, Dr Moitry); INSERM, Lille University Hospital, Pasteur Institute of Lille, U1167 - RID-AGE - Risk factors and molecular determinants of aging-related diseases, F-59000 Lille, France (Dr. Dallongeville, Dr Cottel); Department of Cardiology B, Toulouse University Hospital, Toulouse, France (Prof. Ferrières)

* Corresponding author:

Professor Jean Ferrières

Department of Cardiology, Toulouse University Hospital, TSA 50032

F-31062 Toulouse Cedex 09, France

Phone: +33 561145 949; Fax: +33 562264240

jean.ferrieres@univ-tlse3.fr 


\section{ABSTRACT}

BACKGROUND: Familial hypercholesterolemia (FH) is known to be underdiagnosed and undertreated. The prevalence of heterozygous FH is estimated to be $1 / 500$. Nevertheless, a recent meta-analysis of screening in the general population seems to show that the prevalence of FH is more likely to be $1 / 250$.

METHODS: Analysis was based on the third French MONICA and MONALISA population surveys. Participants were randomly recruited in 1995 and 2005 from the general population of three regions of France. FH was diagnosed using a modified version of the Dutch Lipid Clinic Network (DLCN) without genetic testing.

RESULTS: The DLCN score was assessed in 7928 participants aged 35-74 years (50\% were men). The prevalence of definite or probable FH was $0.85 \%$ [95\% CI: 0.63-1.06]. Among subjects with definite or probable FH, $12 \%$ had a history of premature cardiovascular disease (versus less than $1 \%$ among subjects without $\mathrm{FH} ; \mathrm{P}<.0001), 70 \%$ were treated $(13 \%$ with highintensity, $83 \%$ with moderate-intensity and $4 \%$ with low-intensity statin therapy), $90 \%$ had cholesterol screening within the past 12 months and $97 \%$ were aware of their hypercholesterolemia. None reached the recommended LDL-C target $(<2.5$ or $<1.8 \mathrm{mmol} / \mathrm{L}$ for subjects in primary prevention versus in secondary prevention or with diabetes, respectively), with a mean distance to target of $3.0 \mathrm{mmol} / \mathrm{L}$.

CONCLUSIONS: In a sample from the French general population aged 35-74 years, the prevalence of FH was close to $1 / 120$ and the subjects with $\mathrm{FH}$ were undertreated. 
BRIEF SUMMARY

Familial hypercholesterolemia $(\mathrm{FH})$ is known to be underdiagnosed and undertreated. The prevalence of FH is unknown in France. The prevalence of FH was close to 1/120. More than 1/4 of subjects with FH were not treated.

\section{KEYWORDS}

Familial hypercholesterolemia; Prevalence; General population; France; Dutch Lipid Clinic Network diagnostic criteria 


\section{INTRODUCTION}

Familial hypercholesterolemia (FH) is known to be underdiagnosed and undertreated whereas patients with $\mathrm{FH}$ are at very high cardiovascular risk [1]. The prevalence of heterozygous FH is estimated at 1/500. Nevertheless, screening in the general population, recently reported in a meta-analysis, seems to show that the prevalence of $\mathrm{FH}$ is more likely to be $1 / 250$ and that it varies by geographical location with a lower prevalence in the European subgroup [2]. Moreover, two later European studies, not included in the meta-analysis, estimated prevalence at $1 / 278$ in the German population [3] and at $1 / 192$ in the Spanish population [4]. The prevalence of FH in the French general population has never been studied. We assessed, for the first time, the prevalence and treatment of $\mathrm{FH}$ in a sample recruited from the French general population.

\section{Methods}

\section{Study population and design}

"A sample of 8171 subjects was randomly recruited from the general population to participate in the third French MONICA [5-8] and MONALISA $[9,10]$ cross-sectional surveys on the prevalence of cardiovascular risk factors in 1995 and 2005. Men and women aged 3574, living in northern (Lille area), north-eastern (Strasbourg area) or south-western France (Toulouse area), were recruited between December 1994 and July 1997 for the MONICA study and between October 2005 and January 2008 for the MONALISA study. Polling lists available in each town hall of the survey areas were used to obtain the stratified random sample. Stratification was applied according to center, town size (rural versus urban), age and sex, in order to obtain 200 subjects in each sex and center 10-year age group $(35-44,45-54,55-64$ years for the MONICA and MONALISA studies; 65-74 years for the MONALISA study). No incentive to participate (in particular no financial incentive) was offered. Written informed 
consent to participate in the study was obtained from each subject after full explanation of the nature of the research. The study protocol was approved by an institutional ethics committee in accordance with French law on human biomedical research and the Declaration of Helsinki.

\section{Questionnaires, measurements of clinical parameters and laboratory methods}

Extensive questionnaires were filled in by specifically trained medical staff during a faceto-face interview with the participant. Information on exposures was collected. Data concerning socio-economic level, previous personal and family medical history, cardiovascular risk factors, lifestyle habits and drug intake were recorded. Lipid-lowering, antihypertensive and hypoglycemic drug use was defined as the current consumption of a drug prescribed by a physician for treating cholesterol, blood pressure or glucose disturbances. The intensity of statin therapy (high, moderate and low-intensity statin therapy) was assessed using the 2013 ACC/AHA blood cholesterol guideline [11]. Cholesterol screening within the past 12 months was determined via self-report together with awareness of hypercholesterolemia using the following question: "Have you ever been told by a doctor or other health professional that your blood cholesterol level was high?". Educational level was assessed by a report of graduation or level of school drop-out. Smoking was categorized as current, former and never smoking. Consumption of cigarettes, cigars, cigarillos and pipe tobacco were taken into account. Alcohol consumption was quantified in grams of alcohol per day with a 7-day recall method of a typical week and was categorized into no current consumption, moderate current consumption (1-2 drinks/day(d) (10-20 grams/d) for men and 1 drink/d for women) and high current consumption ( $\geq 3$ drinks/d for men and $\geq 2$ drinks/d for women). Four levels of leisure time physical activity were defined: no regular physical activity, low physical activity (such as walking or bicycling, without causing shortness of breath or sweating, almost every week), moderate physical activity (i.e. causing shortness of breath or sweating, during at least 20 minutes, once or twice a week) 
and high physical activity (i.e. causing shortness of breath or sweating, during at least 20 minutes, three times a week or more). Height, weight and arterial blood pressure (mean of two measurements performed with a standard sphygmomanometer in a sitting position after at least a 5-minute rest) were measured according to standardized protocols by the medical staff. Body mass index (BMI) was calculated as weight divided by the square of height in meters $(\mathrm{kg} / \mathrm{m} 2)$.

\section{Laboratory methods}

Blood samples were taken after at least 10 hours of overnight fasting. Serum total cholesterol and triglycerides were measured by enzymatic assays (Boehringer, Mannheim, Germany). High density lipoprotein cholesterol (HDL-cholesterol) measurement was performed after sodium phosphotungstate-magnesium chloride precipitation of apo B-containing lipoproteins. Low density lipoprotein cholesterol (LDL-cholesterol) was determined by the Friedewald formula when triglycerides were below $4.6 \mathrm{mmol} / \mathrm{L}$ (400 mg/dL) [12]. Fasting blood glucose (FBG) levels were measured using a conventional enzymatic method based on hexokinase-glucose-6phosphate deshydrogenase." All blood samples were analyzed in a core laboratory (Toulouse University Hospital for the MONICA study and the Pasteur Institute of Lille for the MONALISA study).

\section{Definition of FH}

FH was diagnosed using the following modified version of the Dutch Lipid Clinic Network (DLCN) diagnostic criteria [13]: first degree relative (parents) with known premature $(<55$ years in men; $<60$ years in women) coronary or vascular (cerebral or peripheral) disease or hypercholesterolemia (1 point); subject with premature coronary artery disease (2 points); subject with premature cerebral or peripheral vascular disease (1 point); LDL-C (LDLcholesterol) $\geq 8.5 \mathrm{mmol} / \mathrm{L}$ ( 8 points), $6.5-8.4 \mathrm{mmol} / \mathrm{L}$ ( 5 points), $5.0-6.4 \mathrm{mmol} / \mathrm{L}$ ( 3 points) or 
4.0-4.9 mmol/L (1 point). Baseline LDL-C was imputed for subjects under statin or ezetimibe treatment using dose- and statin- or ezetimibe-specific correction factors that have been previously validated [14]. FH was considered as definite, probable, possible or unlikely for a total $>8$, equal to $6-8,3-5$ or $<3$ points, respectively. Subjects with potential secondary hypercholesterolemia (hypothyroidism, chronic renal failure, chronic liver disease or cirrhosis without fatty liver) or mixed dyslipidemia (triglycerides $>3.4 \mathrm{mmol} / \mathrm{L}$ ) were not considered to have FH. Among the 8171 participants, 243 (3\%) had missing data for the DLCN score (LDLC), thus leading to a sample of 7928 subjects analyzed.

\section{Statistical analysis}

Statistical analysis was performed on STATA statistical software, release 14.2 (STATA Corporation, College Station, TX, USA).

We first described the main characteristics of the participants according to definite, probable, possible or unlikely FH (Table S1 in Supplementary Materials). The prevalence of FH was presented as a percentage together with the $95 \%$ confidence interval $[95 \% \mathrm{CI}]$. The prevalence of FH was weighted according to the age and sex distribution of the 35-74 year old populations in the French 1995 and 2005 censuses (in Lille, Strasbourg and Toulouse areas) using Taylor linearization $[15,16]$ (Table 1). We then compared the main characteristics of the participants with and without definite or probable FH (Table 2). Categorical variables were compared between groups using the $\chi^{2}$-test (or Fisher's exact test when necessary). Student's t-test was used to compare the distribution of continuous data (Mann-Whitney's test was used when the distribution departed significantly from normality or when homoscedasticity was rejected). Lastly, we assessed whether FH was independently associated with premature cardiovascular disease using logistic regression (Table 3). Variables initially introduced into the multivariate analyses were standard cardiovascular risk factors associated with premature cardiovascular 
disease in univariate analyses with a $P$-value $<.20$. A backward analysis was then applied until only variables significantly and independently associated with premature cardiovascular disease $(P$-value $<.05)$ remained. When the linearity hypothesis was not respected, continuous variables were transformed into ordered data. Interactions between independent covariates were tested in the final models. None were significant. All reported $P$-values were two-sided and the significance threshold was $<.05$.

\section{Results}

The DLCN score was assessed in 7928 participants $(n=3260$ for the MONICA study and 4668 for the MONALISA study) aged 35-74 years, of whom 50\% were men. The main characteristics of the participants according to DLCN diagnostic criteria for $\mathrm{FH}$ are detailed in Table S1 (in Supplementary Materials).

The prevalence of definite or probable FH was $0.85 \%$ [95\% CI: 0.63-1.06] (Table 1). This prevalence tended to be higher for men and increased according to age, without reaching the significant threshold.

As expected, the frequency of DLCN criteria (such as a personal or family history of premature coronary artery disease, cerebral or peripheral vascular disease) and LDL-C levels were significantly higher in subjects with definite or probable FH. On the other hand, levels of standard cardiovascular risk factors not included in the DLCN score did not significantly differ between subjects with and without definite or probable FH (Table 2).

Among subjects with definite or probable FH $(\mathrm{n}=67), 12 \%$ had premature coronary artery disease, cerebral or peripheral vascular disease (versus less than $1 \%$ among subjects without $\mathrm{FH}$; odds ratio $(\mathrm{OR})=17.6[8.1-38.5] ; P<.001)$. After adjustment for standard cardiovascular risk factors, FH was still significantly and independently associated with premature cardiovascular disease $(\mathrm{OR}=14.1[6.3-31.7] ; P<.001)$ (Table 3). This was also true according 
to age with adjusted $\mathrm{OR}=18.8[1.5-240.1](P=.024), 15.2[5.2-45.1](P<.001)$ and $19.7[4.0-$ 97.5] $(P<.001)$ for subjects aged 35-44, 45-54 and 55-74 years, respectively.

On the other hand, $70 \%(n=47)$ of the subjects with definite or probable FH were treated, $13 \%(n=6)$ with high-intensity statin therapy $(n=3$ with atorvastatin $40 \mathrm{mg}, \mathrm{n}=3$ with rosuvastatin $20 \mathrm{mg}), 83 \%(\mathrm{n}=39)$ with moderate-intensity statin therapy $(\mathrm{n}=11$ with pravastatin $40 \mathrm{mg}, \mathrm{n}=8$ with simvastatin $20 \mathrm{mg}, \mathrm{n}=1$ with simvastatin $40 \mathrm{mg}, \mathrm{n}=4$ with atorvastatin $10 \mathrm{mg}, \mathrm{n}=7$ with atorvastatin $20 \mathrm{mg}, \mathrm{n}=1$ with rosuvastatin $5 \mathrm{mg}, \mathrm{n}=5$ with rosuvastatin $10 \mathrm{mg}, \mathrm{n}=1$ with fluvastatin $40 \mathrm{mg}, \mathrm{n}=1$ with simvastatin $20 \mathrm{mg}$ and ezetimibe $10 \mathrm{mg})$ and $4 \%(\mathrm{n}=2)$ with low-intensity statin therapy $(\mathrm{n}=1$ with pravastatin $10 \mathrm{mg}$ and $\mathrm{n}=$ 1 with pravastatin $20 \mathrm{mg}$ ). These frequencies of treatment were the same in 1995 and 2005 whereas mean LDL-C was significantly lower in 2005 (5.1 mmol/L (standard deviation \pm 1.3 ) versus $6.2 \mathrm{mmol} / \mathrm{L}( \pm 1.7)$ in $1995 ; P=.0144)$. The frequency of high- or moderate-intensity statin therapy was significantly higher for treated subjects with definite or probable FH than for treated subjects with possible or unlikely FH (Figure 1).

None of the subjects with definite or probable FH reached the recommended target [1] (LDL$\mathrm{C}<2.5 \mathrm{mmol} / \mathrm{L}$ or $<1.8 \mathrm{mmol} / \mathrm{L}$ for subjects in primary prevention versus in secondary prevention or with diabetes, respectively), whereas $90 \%(n=60)$ had cholesterol testing within the past 12 months and $97 \%(n=65)$ were aware of their hypercholesterolemia. Mean measured LDL-C was $4.9 \mathrm{mmol} / \mathrm{L}( \pm 1.0)$ and $6.6 \mathrm{mmol} / \mathrm{L}( \pm 1.7)$ in subjects with definite or probable FH with and without treatment, respectively $(P<.0001)$, and the mean distance to target was $3.0 \mathrm{mmol} / \mathrm{L}( \pm 1.5)$

\section{Discussion}

\section{Prevalence of FH}


In the French general population aged 35-74 years, we described for the first time, in nearly 8000 participants, a prevalence of definite or probable FH of $0.85 \%$ [95\% CI: $0.63-1.06$ ]. This is significantly higher than the pooled prevalence of $\mathrm{FH}$ estimated in the recent meta-analysis of Akioyamen et al. (0.40\% [95\% CI: 0.29-0.54]; $\mathrm{n}=19$ studies; $\mathrm{n}=2,458,456$ subjects [2]). This difference is explained by the method of correction of the LDL-C. We corrected LDL-C for subjects under statins or ezetimibe using dose- and statin- or ezetimibe-specific correction factors recently validated [14], whereas all the studies included in the meta-analysis of Akioyamen et al. which corrected LDL-C, had multiplied by 1.43 (corresponding to an estimated $30 \%$ reduction) [17-23]. In a sensitivity analysis, we assessed the prevalence of FH using this method of correction (LDL-C x 1.43) and the prevalence was very close to the result of Akioyamen et al. (0.41\% [95\% CI: 0.27-0.56] versus $0.40 \%$ [95\% CI: $0.29-0.54])$. Moreover, whereas the prevalence of FH is expected to decrease with age (considering that FH is a genetic disease with a very high risk of premature cardiovascular death), we found that it tended to increase with age. Akioyamen et al. showed, similarly, that the pooled prevalence of FH increased according to age with a peak between 60-69 years and a decline thereafter. Moreover, we found that the prevalence of FH tended to be higher in men similarly to the results of Zamora et al. [4]. These unexpected higher prevalences may be due to the use of FH diagnostic criteria based on LDL-C which is known to increase with age and which is lower in premenopausal women $[23,24]$. Finally, in the meta-analysis of Akioyamen et al., the prevalence of FH was significantly lower in the European subgroup $(0.21 \%$ [95\% CI: $0.14-$ 0.28]). This lower prevalence seems to be linked to the diagnostic method used. Half of the studies included in the European meta-analysis subgroup used DNA-based evidence of mutations, which is known to be associated with lower prevalence of FH $[19,21,25]$. Accordingly, Séguro et al. showed that an FH mutation was identified in only $57 \%$ of patients with clinical FH [26]. In French-Canadian population, FH seems to be more prevalent because 
of genetic founder effect with a prevalence reaching 1/81 in one region of the Province of Quebec [27].

\section{Management of FH}

Screening of $\mathrm{FH}$ is recommended by French experts for high-risk patients (patients with premature cardiovascular disease or with a family history of premature cardiovascular disease or high cholesterol or tendon xanthomas, or when LDL-C $>5 \mathrm{mmol} / \mathrm{L}$ ) in order to identify $\mathrm{FH}$ as soon as possible and initiate adequate therapy [28]. The treatment strategy recommended by French experts is based on high-intensity statin in combination with ezetimibe and bile acid sequestrant in order to obtain $\geq 50 \%$ reduction in LDL-C [28]. For severe FH, if the reduction of LDL-C failed to obtain the target, the addition of a PCSK9 inhibitor should be considered [28]. This French treatment strategy is very closed to the guidelines of Canadian experts $[29,30]$. In our population based-survey, only $70 \%$ of subjects with definite or probable FH were treated and none reached the recommended LDL-C target [1] (LDL-C $<2.5 \mathrm{mmol} / \mathrm{L}$ or $<1.8 \mathrm{mmol} / \mathrm{L}$ for subjects in primary prevention versus in secondary prevention or with diabetes, respectively) with a mean distance to target of $3.0 \mathrm{mmol} / \mathrm{L}$. These results were concordant with the contemporary trend in the management of FH in Canada, although in the Canadian study the average distance to target in FH patients was $1.7 \mathrm{mmol} / \mathrm{L}$ [31]. Moreover, in our population based-survey, $\mathrm{FH}$ is independently associated with premature cardiovascular disease (adjusted $\mathrm{OR}=14.1[6.3-31.7] ; P<.001)$. Our findings confirmed that, despite the very high associated cardiovascular risk [21,32], FH is undertreated [1,4,33,34]. This may be explained by the fact that French physicians involved in the management of the disease seems to have a lack of knowledge of $\mathrm{FH}$ and its associated cardiovascular risk [35]. Perhaps, in the context of the "French Paradox" (low incidence of coronary artery disease in Southern Europe) [36], French physicians think that FH patients have also a lower coronary artery disease risk 
than other FH patients in other parts in the World. Currently, three care pathways, involving general practitioners, cardiologists, endocrinologists, pharmacists and medical laboratories were launched in 2018 in three French regions (Nantes, Toulouse and Marseille Regions) in order to improve the knowledge, the diagnostic and the management of FH [37]. Results will be available in the next 3 years and should improve the screening and the treatment of $\mathrm{FH}$ in France.

\section{Strengths and limitations of the study}

The main limitation of our study is the use of a modified version of the DLCN criteria, without genetic testing and with the possibility of overestimation of the prevalence of $\mathrm{FH}$. Nevertheless, modified DLCN criteria without genetic testing are those most frequently used in studies assessing FH in population surveys [2]. Moreover, the use of clinical criteria without genetic testing has demonstrated good diagnostic [38] and predictive [39] performance, leading Canadian researchers to publish a novel simplified definition which takes DNA-negative patients into consideration $[29,40,41]$. The strength of our study is that it is the first to be conducted in a representative sample of the French general population [7] with nearly 8000 participants (and with LDL-C levels analyzed in core laboratories). Only two studies have assessed the prevalence of FH in France, but the first was conducted in statin-treated patients [42] and the second used a large database of patients of a French university hospital [43]. These studies were not representative of the French general population. Moreover, we can consider that our study was the first to be conducted in the general population in southern Europe. The other two studies conducted in southern Europe (in Spain [4] and in Italy [44]) used primary care patients and the SAFEHEART Spanish registry includes only FH with genetic diagnosis [45], underestimating the number of $\mathrm{FH}[4,25]$. 


\section{Conclusions}

In the French general population aged 35-74 years, the prevalence of FH was close to 1/120 and subjects with FH were undertreated. 
Figure legend:

Figure 1 Frequency of low, moderate and high-intensity statin therapy in treated subjects with definite/probable, possible or unlikely familial hypercholesterolemia (FH) according to the Dutch Lipid Clinic Network criteria (DLCN)

DLCN (modified version of the Dutch Lipid Clinic Network criteria): first degree relative (parents) with known premature ( $<55$ years in men; $<60$ years in women) coronary or vascular (cerebral or peripheral) disease or hyperlipidemia (1 point); subject with premature coronary artery disease ( 2 points); subject with premature cerebral or peripheral vascular disease ( 1 point); LDL-C $\geq 8.5 \mathrm{mmol} / \mathrm{L}$ (8 points), $6.5-$ $8.4 \mathrm{mmol} / \mathrm{L}$ ( 5 points), $5.0-6.4 \mathrm{mmol} / \mathrm{L}$ (3 points), $4.0-4.9 \mathrm{mmol} / \mathrm{L}$ (1 point). LDL-C was corrected (using dose- and statin- or ezetimibe-specific correction factors [14]) for subjects under statins or ezetimibe. Familial hypercholesterolemia $(\mathrm{FH})$ was considered as definite, probable, possible or unlikely for a total $>8$, equal to $6-8,3-5$ or $<3$ points, respectively. The intensity of statin therapy (high, moderate and low) was assessed using the 2013 ACC/AHA blood cholesterol guideline [11]. 


\section{Acknowledgments}

Authors would like to thank nurses, physicians, dieticians, computer scientists and secretaries of Lille, Strasbourg and Toulouse and the Centre de Médecine Préventive de Lille, the Laboratoire d'Analyses Génomiques and the Service de Biologie Spécialisée de l'Institut Pasteur de Lille, the Centre de Santé de la MGEN de Strasbourg, the Unité de Coordination de la Biologie des Essais Cliniques des Hôpitaux Universitaires de Strasbourg, the Departments of Cardiology of the Toulouse University Hospital, the Institut National de la Statistique et des Études Économiques (INSEE) and the city halls which have participated in the three regions.

This article is dedicated to Robert Dufour, a fellow traveller in lipidology.

\section{Funding Sources}

This work was supported by the Institut National de la Santé et de la Recherche Médicale (INSERM), the Direction Générale de la Santé (DGS), the Institut Pasteur de Lille, the University Hospital of Lille, the Fonds d'intervention en Santé Publique, the Mutuelle Générale de l'Education Nationale, ONIVINS, the Fondation de France, the CPAM of Sélestat, the Fédération Française de Cardiologie, the Conseil Régional du Nord-Pas de Calais, Parke-Davis, Bayer Pharmaceuticals, and the Centre de Recherche et d'Information Nutritionnelles (CERIN). The MONALISA Study was made possible by an unrestricted grant of Pfizer and by a grant from ANR (ANR-05-PNRA-018).

The sponsors did not take part or interfere in the collection, analysis and interpretation of the data, in the writing of the report, or in the decision to submit the article for publication. 


\section{Disclosures}

J.F. has received travel expenses, payment for speaking at meetings and funding for research from Amgen, Akcea, Astra Zeneca, MSD, Sanofi and Servier. The other authors have nothing to declare. 


\section{References}

1. Nordestgaard BG, Chapman MJ, Humphries SE, et al.; European Atherosclerosis Society Consensus Panel. Familial hypercholesterolaemia is underdiagnosed and undertreated in the general population: guidance for clinicians to prevent coronary heart disease: consensus statement of the European Atherosclerosis Society. Eur Heart J. 2013;34:3478-3490a.

2. Akioyamen LE, Genest J, Shan SD, et al. Estimating the prevalence of heterozygous familial hypercholesterolaemia: a systematic review and meta-analysis. BMJ Open. 2017;7:e016461.

3. Schmidt N, Schmidt B, Dressel A, et al. Familial hypercholesterolemia in primary care in Germany. Diabetes and cardiovascular risk evaluation: Targets and Essential Data for Commitment of Treatment (DETECT) study. Atherosclerosis. 2017;266:24-30.

4. Zamora A, Masana L, Comas-Cufí M, et al.; XULA and ISV-Girona groups. Familial hypercholesterolemia in a European Mediterranean population-Prevalence and clinical data from 2.5 million primary care patients. J Clin Lipidol. 2017;11:1013-1022.

5. Bérard E, Bongard V, Dallongeville J, et al. Impact of cardiovascular risk factor control on long-term cardiovascular and all-cause mortality in the general population. Ann Med. 2016;48:559-567.

6. Bérard E, Bongard V, Haas B, et al. Score of adherence to 2016 European cardiovascular prevention guidelines predicts cardiovascular and all-cause mortality in the general population. Can J Cardiol. 2017;33:1298-1304.

7. Bérard E, Séguro F, Bongard V, et al. Predictive accuracy of the European Society of Cardiology SCORE among French people. J Cardiopulm Rehabil Prev. 2016;36:38-48.

8. Marques-Vidal P, Ruidavets JB, Amouyel P, et al. Change in cardiovascular risk factors in France, 1985-1997. Eur J Epidemiol. 2004;19:25-32. 
9. Bongard V, Dallongeville J, Arveiler D, et al. Attainment of low-density lipoprotein cholesterol target in the French general population according to levels of cardiovascular risk: Insights from the MONA LISA study. Arch Cardiovasc Dis. 2013;106:93-102.

10. Bongard V, Arveiler D, Dallongeville J, et al. Food groups associated with a reduced risk of 15-year all-cause death. Eur J Clin Nutr. 2016;70:715-722.

11. Stone NJ, Robinson JG, Lichtenstein AH, et al.; American College of Cardiology/American Heart Association Task Force on Practice Guidelines. 2013 ACC/AHA guideline on the treatment of blood cholesterol to reduce atherosclerotic cardiovascular risk in adults: a report of the American College of Cardiology/American Heart Association Task Force on Practice Guidelines. Circulation. 2014;129:S1-45. Erratum in: Circulation. 2015;132:e396. Circulation. 2014;129:S46-48.

12. Friedewald WT, Levy RI, Fredrickson DS. Estimation of the concentration of low density lipoprotein cholesterol in plasma without use of the preparative ultracentrifuge. Clin Chem. 1978;18:499-502.

13. Haase A, Goldberg AC. Identification of people with heterozygous familial hypercholesterolemia. Curr Opin Lipidol. 2012;23:282-289.

14. Ruel I, Aljenedil S, Sadri I, et al. Imputation of Baseline LDL Cholesterol Concentration in Patients with Familial Hypercholesterolemia on Statins or Ezetimibe. Clin Chem. 2018;64:355362.

15. Shah BV. Linearization methods of variance estimation. In: Armitage P, Colton T, eds. Encyclopedia of Biostatistics. $2^{\text {nd }}$ ed. Chichester, England: John Wiley and Sons Ltd; 1998: $2276-2279$

16. Wolter KM. Introduction to Variance Estimation. 2nd ed. New York: Springer; 2007. 
17. Shi Z, Yuan B, Zhao D, Taylor AW, Lin J, Watts GF. Familial hypercholesterolemia in China: prevalence and evidence of underdetection and undertreatment in a community population. Int J Cardiol. 2014;174:834-836.

18. Watts GF, Shaw JE, Pang J, Magliano DJ, Jennings GL, Carrington MJ. Prevalence and treatment of familial hypercholesterolaemia in Australian communities. Int J Cardiol. 2015;185:69-71.

19. Benn M, Watts GF, Tybjærg-Hansen A, Nordestgaard BG. Mutations causative of familial hypercholesterolaemia: screening of 98098 individuals from the Copenhagen General Population Study estimated a prevalence of 1 in 217. Eur Heart J. 2016;37:1384-1394.

20. Catapano AL, Lautsch D, Tokgözoglu L, et al. Prevalence of potential familial hypercholesteremia $(\mathrm{FH})$ in 54,811 statin-treated patients in clinical practice. Atherosclerosis. 2016;252:1-8.

21. Khera AV, Won HH, Peloso GM, et al. Diagnostic yield and clinical utility of sequencing familial hypercholesterolemia genes in patients with severe hypercholesterolemia. J Am Coll Cardiol. 2016;67:2578-2589.

22. Pang J, Martin AC, Mori TA, Beilin LJ, Watts GF. Prevalence of Familial Hypercholesterolemia in Adolescents: Potential Value of Universal Screening? J Pediatr. 2016;170:315-316.

23. De Ferranti SD, Rodday AM, Mendelson MM, Wong JB, Leslie LK, Sheldrick RC. Prevalence of familial hypercholesterolemia in the 1999 to 2012 United States National Health and Nutrition Examination Surveys (NHANES). Circulation. 2016;133:1067-1072.

24. Wang X, Magkos F, Mittendorfer B. Sex differences in lipid and lipoprotein metabolism: it's not just about sex hormones. J Clin Endocrinol Metab. 2011;96:885-893.

25. Catapano AL, Graham I, De Backer G, et al.; ESC Scientific Document Group. 2016 ESC/EAS guidelines for the management of dyslipidaemias. Eur Heart J. 2016;37:2999-3058. 
26. Séguro F, Rabès JP, Taraszkiewicz D, Ruidavets JB, Bongard V, Ferrières J. Genetic diagnosis of familial hypercholesterolemia is associated with a premature and high coronary heart disease risk. Clin Cardiol. 2018;41:385-391.

27. Paquette M, Genest J, Baass A. Familial hypercholesterolemia: experience from the FrenchCanadian population. Curr Opin Lipidol. 2018;29:59-64.

28. Farnier M, Civeira F, Descamps O; FH expert working group. How to implement clinical guidelines to optimise familial hypercholesterolaemia diagnosis and treatment. Atheroscler Suppl. 2017;26:25-35.

29. Brunham LR, Ruel I, Aljenedil S, et al. Canadian Cardiovascular Society Position Statement on Familial Hypercholesterolemia: Update 2018. Can J Cardiol. 2018;34:1553-1563.

30. Baass A, Hegele RA. Getting Real With PCSK9 Inhibitors in Familial Hypercholesterolemia. Can J Cardiol. 2018;34:959-961.

31. Brunham LR, Cermakova L, Lee T, et al. Contemporary Trends in the Management and Outcomes of Patients With Familial Hypercholesterolemia in Canada: A Prospective Observational Study. Can J Cardiol. 2017;33:385-392.

32. Abul-Husn NS, Manickam K, Jones LK, et al. Genetic identification of familial hypercholesterolemia within a single U.S. health care system. Science. 2016;354.

33. Bucholz EM, Rodday AM, Kolor K, Khoury MJ, de Ferranti SD. Prevalence and predictors of cholesterol screening, awareness, and statin treatment among US adults with familial hypercholesterolemia or other forms of severe dyslipidemia (1999-2014). Circulation. 2018;137:2218-2230.

34. Rodriguez F, Knowles JW, Maron DJ, Virani SS, Heidenreich PA. Frequency of statin use in patients with low-density lipoprotein cholesterol $\geq 190 \mathrm{mg} / \mathrm{dl}$ from the Veterans Affairs Health System. Am J Cardiol. 2018;122:756-761. 
35. Ferrières J, Bruckert É, Béliard S, et al. Familial hypercholesterolemia: A largely underestimated cardiovascular risk. Ann Cardiol Angeiol. 2018;67:1-8.

36. Ferrières J. The French paradox: lessons for other countries. Heart. 2004;90(1):107-11.

37. Rabès JP, Béliard S, Carrié A. Familial hypercholesterolemia: experience from France. Curr Opin Lipidol. 2018;29:65-71.

38. Civeira F, Ros E, Jarauta E, et al. Comparison of genetic versus clinical diagnosis in familial hypercholesterolemia. Am J Cardiol. 2008;102:1187-1193.

39. Séguro F, Bongard V, Bérard E, Taraszkiewicz D, Ruidavets JB, Ferrières J. Dutch Lipid Clinic Network low-density lipoprotein cholesterol criteria are associated with long-term mortality in the general population. Arch Cardiovasc Dis. 2015;108:511-518.

40. Ruel I, Brisson D, Aljenedil S, et al. Simplified Canadian definition for familial hypercholesterolemia. Can J Cardiol. 2018;34:1210-1214.

41. McPherson R. The Cardiovascular Burden of Undiagnosed Familial Hypercholesterolemia: Need to Modify Guidelines to Encourage Earlier Diagnosis and Therapy. Can J Cardiol. 2018;34:1112-1113.

42. Catapano AL, Lautsch D, Tokgözoglu L, et al. Prevalence of potential familial hypercholesteremia (FH) in 54,811 statin-treated patients in clinical practice. Atherosclerosis. 2016;252:1-8.

43. Ferrieres J, Combis MS, Verdier C, et al. Big data and lipoproteins: prevalence of dyslipidemias in 100762 individuals. Eur Heart J. 2016;37(Abstract Supplement):11.

44. Guglielmi V, Bellia A, Pecchioli S, et al. What is the actual epidemiology of familial hypercholesterolemia in Italy? evidence from a national primary care database. Int J Cardiol. 2016;223:701-705. 
45. Mata N, Alonso R, Badimón L, et al. Clinical characteristics and evaluation of LDLcholesterol treatment of the Spanish Familial Hypercholesterolemia Longitudinal Cohort Study (SAFEHEART). Lipids Health Dis. 2011;10:94. 
Figure 1 Frequency of low, moderate and high-intensity statin therapy in treated subjects with definite/probable, possible or unlikely familial hypercholesterolemia (FH) according to the Dutch Lipid Clinic Network criteria (DLCN)

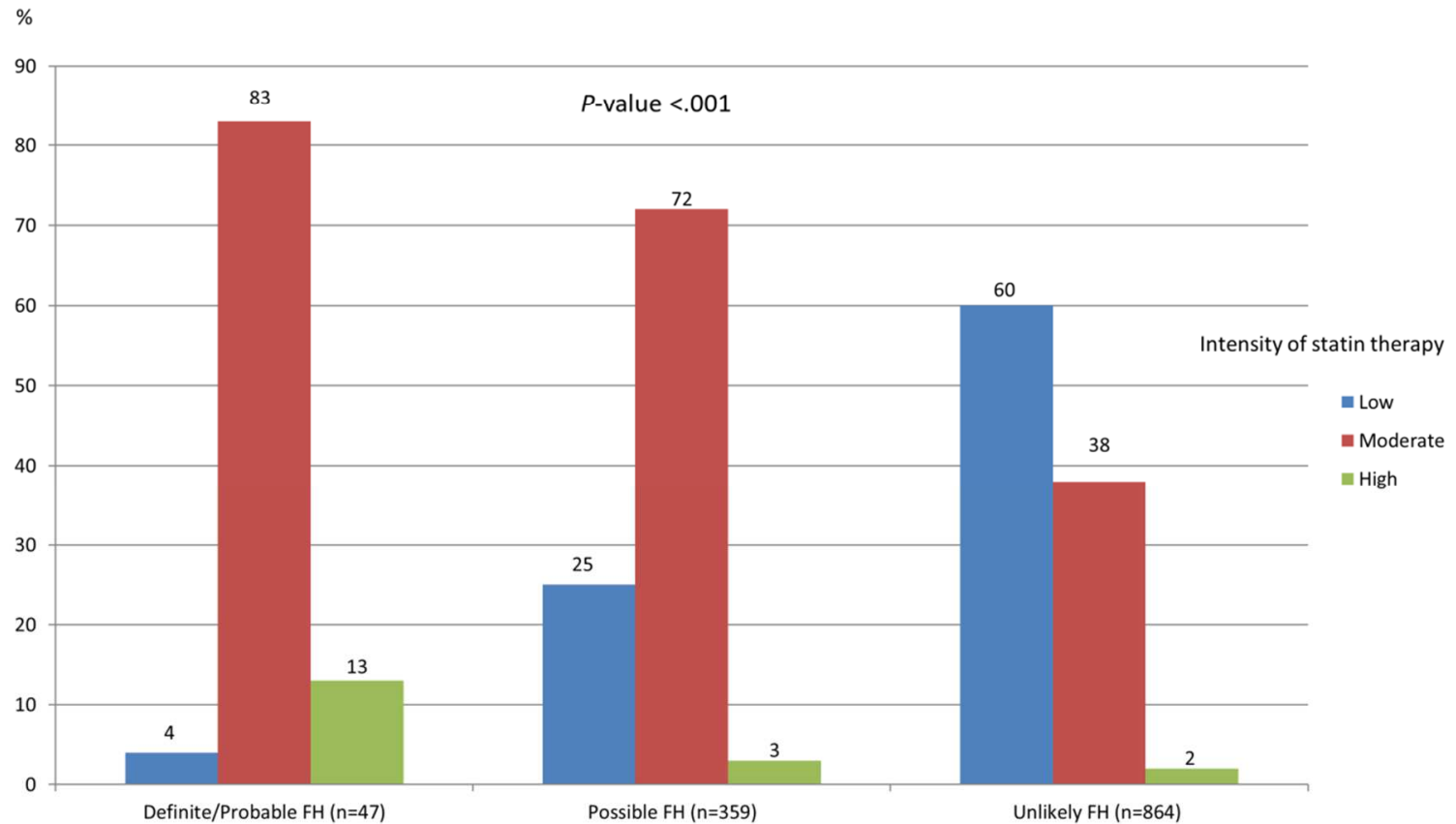

DLCN (modified version of the Dutch Lipid Clinic Network criteria): first degree relative (parents) with known premature ( $<55$ years in men; $<60$ years in women) coronary or vascular (cerebral or peripheral) disease or hyperlipidemia (1 point); subject with premature coronary artery disease (2 points); subject with premature cerebral or peripheral vascular disease ( 1 point); LDL-C $\geq 8.5 \mathrm{mmol} / \mathrm{L}$ (8 points), $6.5-$ $8.4 \mathrm{mmol} / \mathrm{L}$ (5 points), $5.0-6.4 \mathrm{mmol} / \mathrm{L}$ (3 points), $4.0-4.9 \mathrm{mmol} / \mathrm{L}$ (1 point). LDL-C was corrected (using dose- and statin- or ezetimibe-specific correction factors [14]) for subjects under statins or ezetimibe. Familial hypercholesterolemia $(\mathrm{FH})$ was considered as definite, probable, possible or unlikely for a total $>8$, equal to $6-8,3-5$ or $<3$ points, respectively. The intensity of statin therapy (high, moderate and low) was assessed using the 2013 ACC/AHA blood cholesterol guideline [11]. 
Table 1 Prevalence* of familial hypercholesterolemia according to age and sex

\begin{tabular}{|c|c|c|c|c|c|c|}
\hline \multirow{3}{*}{ Age, y } & \multicolumn{6}{|c|}{ FH $\quad$ (DLCN), $\frac{\circ}{[95 \%}$ CI $]$} \\
\hline & \multicolumn{3}{|c|}{ Possible FH } & \multicolumn{3}{|c|}{ Probable or Definite FH } \\
\hline & Men & Women & Total & Men & Women & Total \\
\hline $35-44$ & $\begin{array}{c}12.6 \\
{[10.6-14.5]}\end{array}$ & $\begin{array}{c}3.97 \\
{[2.83-5.11]}\end{array}$ & $\begin{array}{c}8.37 \\
{[7.22-9.51]}\end{array}$ & $\begin{array}{c}0.69 \\
{[0.21-1.18]}\end{array}$ & $\begin{array}{c}0.18 \\
{[0.00-0.44]}\end{array}$ & $\begin{array}{c}0.44 \\
{[0.17-0.72]}\end{array}$ \\
\hline $45-54$ & $\begin{array}{c}15.6 \\
{[13.4-17.7]}\end{array}$ & $\begin{array}{c}8.14 \\
{[6.51-9.76]}\end{array}$ & $\begin{array}{c}11.9 \\
{[10.6-13.3]}\end{array}$ & $\begin{array}{c}0.94 \\
{[0.38-1.51]}\end{array}$ & $\begin{array}{c}0.91 \\
{[0.34-1.49]}\end{array}$ & $\begin{array}{c}0.93 \\
{[0.53-1.33]}\end{array}$ \\
\hline $55-64$ & $\begin{array}{c}14.4 \\
{[12.3-16.5]}\end{array}$ & $\begin{array}{c}15.0 \\
{[12.9-17.2]}\end{array}$ & $\begin{array}{c}14.7 \\
{[13.2-16.2]}\end{array}$ & $\begin{array}{c}0.98 \\
{[0.39-1.56]}\end{array}$ & $\begin{array}{c}1.02 \\
{[0.41-1.63]}\end{array}$ & $\begin{array}{c}1.00 \\
{[0.58-1.42]}\end{array}$ \\
\hline $65-74$ & $\begin{array}{c}13.7 \\
{[10.9-16.6]}\end{array}$ & $\begin{array}{c}17.9 \\
{[14.6-21.1]}\end{array}$ & $\begin{array}{c}15.9 \\
{[13.8-18.1]}\end{array}$ & $\begin{array}{c}0.82 \\
{[0.10-1.53]}\end{array}$ & $\begin{array}{c}1.57 \\
{[0.54-2.59]}\end{array}$ & $\begin{array}{c}1.22 \\
{[0.58-1.87]}\end{array}$ \\
\hline Total & $\begin{array}{c}13.6 \\
{[12.5-14.7]}\end{array}$ & $\begin{array}{c}9.00 \\
{[8.13-9.87]}\end{array}$ & $\begin{array}{c}11.3 \\
{[10.6-12.0]}\end{array}$ & $\begin{array}{c}0.89 \\
{[0.58-1.19]}\end{array}$ & $\begin{array}{c}0.80 \\
{[0.51-1.10]}\end{array}$ & $\begin{array}{c}0.85 \\
{[0.63-1.06]}\end{array}$ \\
\hline
\end{tabular}

DLCN (modified version of the Dutch Lipid Clinic Network criteria): first degree relative (parents) with known premature ( $<55$ years in men; $<60$ years in women) coronary or vascular (cerebral or peripheral) disease or hyperlipidemia (1 point); subject with premature coronary artery disease (2 points); subject with premature cerebral or peripheral vascular disease ( 1 point); LDL-C $\geq 8.5 \mathrm{mmol} / \mathrm{L}$ (8 points), $6.5-$ $8.4 \mathrm{mmol} / \mathrm{L}$ (5 points), $5.0-6.4 \mathrm{mmol} / \mathrm{L}$ (3 points), $4.0-4.9 \mathrm{mmol} / \mathrm{L}$ (1 point). LDL-C was corrected (using dose- and statin- or ezetimibe-specific correction factors [14]) for subjects under statins or ezetimibe. Familial hypercholesterolemia (FH) was considered as definite, probable or possible for a total $>8$, equal to $6-8$ or 3-5 points, respectively.

$95 \% \mathrm{Cl}, 95 \%$ confidence interval.

* Weighted according to the age and sex distribution of the population aged 35-74 years in the French 1995 and 2005 censuses. 
Table 2 Comparison of the main characteristics of the participants with and without definite or probable familial hypercholesterolemia (defined by the Dutch Lipid Clinic Network criteria)

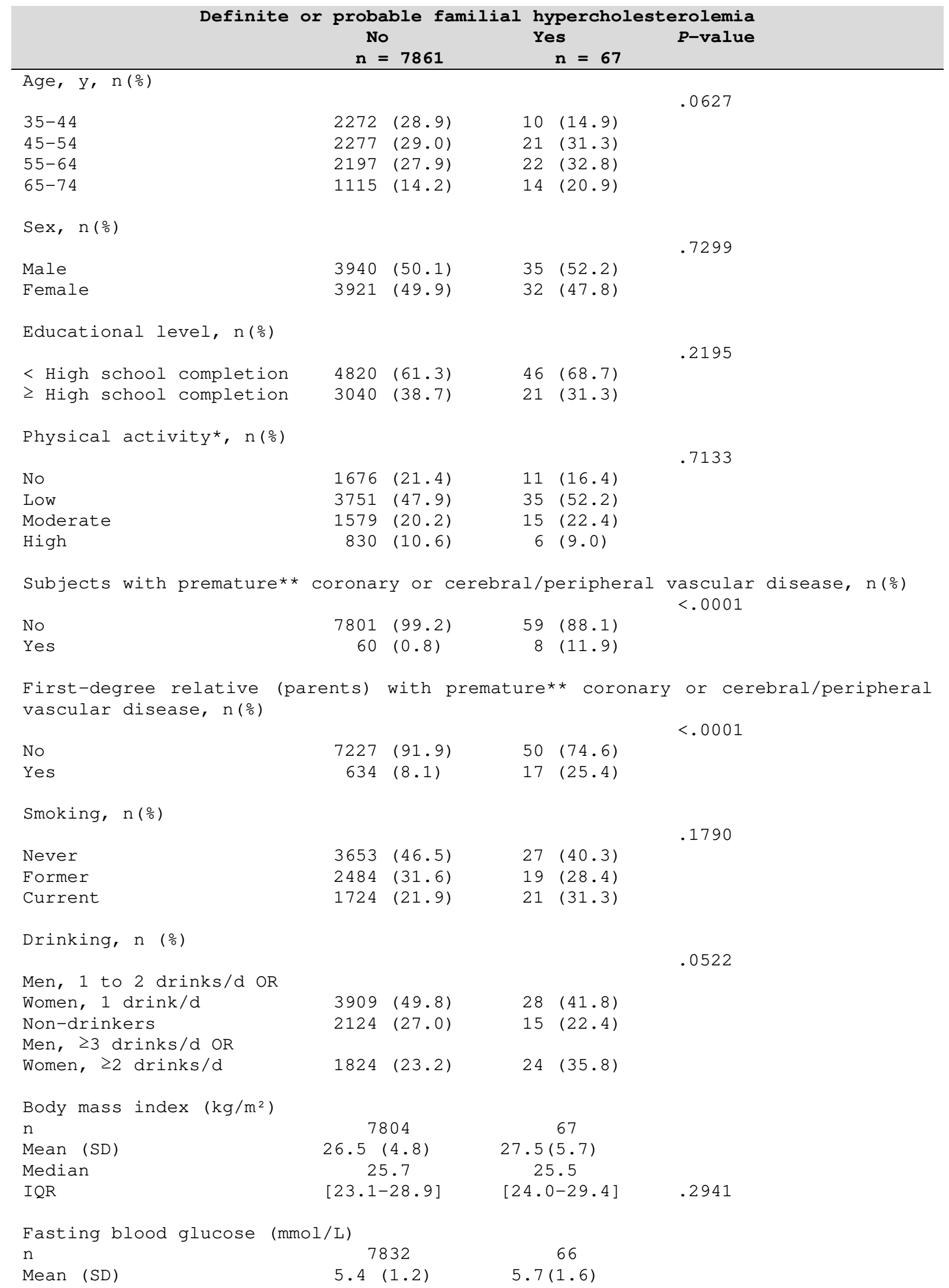




\begin{tabular}{|c|c|c|c|}
\hline Median & 5.2 & 5.4 & \\
\hline IQR & {$[4.9-5.7]$} & {$[5.1-5.8]$} & .0272 \\
\hline \multicolumn{4}{|l|}{ Diabetes $* * *, n\left(\frac{\circ}{0}\right)$} \\
\hline No & $7347 \quad(93.5)$ & $62(92.5)$ & \\
\hline Yes & $514 \quad(6.5)$ & $5(7.5)$ & \\
\hline \multicolumn{4}{|c|}{ Systolic blood pressure (mmHg) } \\
\hline $\mathrm{n}$ & 7844 & 67 & \\
\hline Mean (SD) & $133.4(20.0)$ & $134.8(18.2)$ & .5873 \\
\hline Median & 131.0 & 132.0 & \\
\hline $\mathrm{IQR}$ & {$[119.5-145.0]$} & {$[121.0-141.5]$} & \\
\hline \multicolumn{4}{|c|}{ Diastolic blood pressure (mmHg) } \\
\hline & 7842 & 67 & \\
\hline Mean (SD) & $81.7 \quad(11.2)$ & $81.6(8.4)$ & \\
\hline Median & 81.0 & 81.5 & \\
\hline $\mathrm{IQR}$ & {$[74.0-88.5]$} & {$[76.5-85.5]$} & .9027 \\
\hline \multicolumn{4}{|l|}{ Blood pressure, $\mathrm{n}\left(\frac{\circ}{0}\right)$} \\
\hline & & & .4985 \\
\hline$<140$ and $90 \mathrm{mmHg}$ & $4834 \quad(61.6)$ & $44 \quad(65.7)$ & \\
\hline$\geq 140$ or $90 \mathrm{mmHg}$ & $3009(38.4)$ & $23(34.3)$ & \\
\hline \multicolumn{4}{|c|}{ Antihypertensive drug treatment, $\mathrm{n}(\%)$} \\
\hline & & & .0751 \\
\hline No & $6315(80.3)$ & $48 \quad(71.6)$ & \\
\hline Yes & $1546(19.7)$ & $19(28.4)$ & \\
\hline \multicolumn{4}{|c|}{ Lipid-lowering drug treatment, $\mathrm{n}\left(\frac{\circ}{0}\right)$} \\
\hline & & & $<.0001$ \\
\hline No & $6638 \quad(84.4)$ & $20 \quad(29.9)$ & \\
\hline Yes & $1223(15.6)$ & $47 \quad(70.1)$ & \\
\hline \multicolumn{4}{|l|}{ Total cholesterol (mmol/L) } \\
\hline $\mathrm{n}$ & 7861 & 67 & \\
\hline Mean (SD) & $5.8(1.0)$ & $7.6(1.5)$ & \\
\hline Median & 5.7 & 7.4 & \\
\hline $\mathrm{IQR}$ & {$[5.1-6.4]$} & {$[6.3-8.7]$} & $<.0001$ \\
\hline \multicolumn{4}{|l|}{ Triglycerides (mmol/L) } \\
\hline $\mathrm{n}$ & 7861 & 67 & \\
\hline Mean (SD) & $1.3(0.7)$ & $1.7(0.7)$ & \\
\hline Median & 1.1 & 1.5 & \\
\hline $\mathrm{IQR}$ & {$[0.8-1.5]$} & {$[1.2-2.0]$} & $<.0001$ \\
\hline \multicolumn{4}{|l|}{ HDL-cholesterol (mmol/L) } \\
\hline & 7861 & 67 & \\
\hline Mean (SD) & $1.5(0.4)$ & $1.5(0.4)$ & .6059 \\
\hline Median & 1.4 & 1.4 & \\
\hline $\mathrm{IQR}$ & {$[1.2-1.7]$} & {$[1.1-1.7]$} & \\
\hline \multicolumn{4}{|l|}{ LDL-cholesterol (mmol/L) } \\
\hline $\mathrm{n}$ & 7861 & 67 & \\
\hline Mean (SD) & $3.7 \quad(0.9)$ & $5.4(1.5)$ & \\
\hline Median & 3.6 & 5.1 & \\
\hline $\mathrm{IQR}$ & {$[3.1-4.3]$} & {$[4.2-6.4]$} & $<.0001$ \\
\hline \multicolumn{4}{|c|}{ 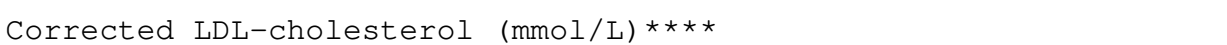 } \\
\hline $\mathrm{n}$ & 7861 & 67 & \\
\hline Mean (SD) & $3.9 \quad(1.0)$ & $8.1(1.6)$ & \\
\hline Median & 3.8 & 8.0 & \\
\hline $\mathrm{IQR}$ & {$[3.2-4.5]$} & {$[6.9-8.7]$} & $<.0001$ \\
\hline \multicolumn{4}{|l|}{ DLCN } \\
\hline $\mathrm{n}$ & 7861 & 67 & \\
\hline Mean (SD) & $0.9 \quad(1.2)$ & $7.0(1.2)$ & \\
\hline
\end{tabular}


DLCN (modified version of the Dutch Lipid Clinic Network criteria): first degree relative (parents) with known premature ( $<55$ years in men; $<60$ years in women) coronary or vascular (cerebral or peripheral) disease or hyperlipidemia (1 point); subject with premature coronary artery disease ( 2 points); subject with premature cerebral or peripheral vascular disease (1 point); LDL-C $\geq 8.5 \mathrm{mmol} / \mathrm{L}$ (8 points), $6.5-8.4 \mathrm{mmol} / \mathrm{L}$ (5 points), $5.0-6.4 \mathrm{mmol} / \mathrm{L}$ ( 3 points) or $4.0-4.9 \mathrm{mmol} / \mathrm{L}$ (1 point). LDL-C was corrected (using dose- and statin- or ezetimibe-specific correction factors [14]) for subjects under statins or ezetimibe. Familial hypercholesterolemia $(\mathrm{FH})$ was considered as definite or probable for a total $>8$ or equal to $6-8$ points, respectively.

$\mathrm{n}$, number; SD, standard deviation; IQR, inter-quartile range; $d$, day.

* No regular physical activity versus low physical activity (such as walking or bicycling, without causing shortness of breath or sweating, almost every week) versus moderate physical activity (i.e. causing shortness of breath or sweating, during at least 20 minutes, once or twice a week) versus high physical activity (i.e. causing shortness of breath or sweating, during at least 20 minutes, three times a week or more)

$* *<55$ years in men; $<60$ years in women

*** Diabetes was assessed for subjects with fasting blood glucose $\geq 7 \mathrm{mmol} / \mathrm{L}(126 \mathrm{mg} / \mathrm{dL}$ ) or under hypoglycemic drug treatment

**** LDL-C was corrected (using dose- and statin- or ezetimibe-specific correction factors [14]) for subjects under statins or ezetimibe. 
Table 3 Independent association of definite or probable familial hypercholesterolemia (defined by the Dutch Lipid Clinic Network criteria) with premature* coronary or cerebral/peripheral vascular disease ( $n=68$ events in the entire study population of 7928 participants)

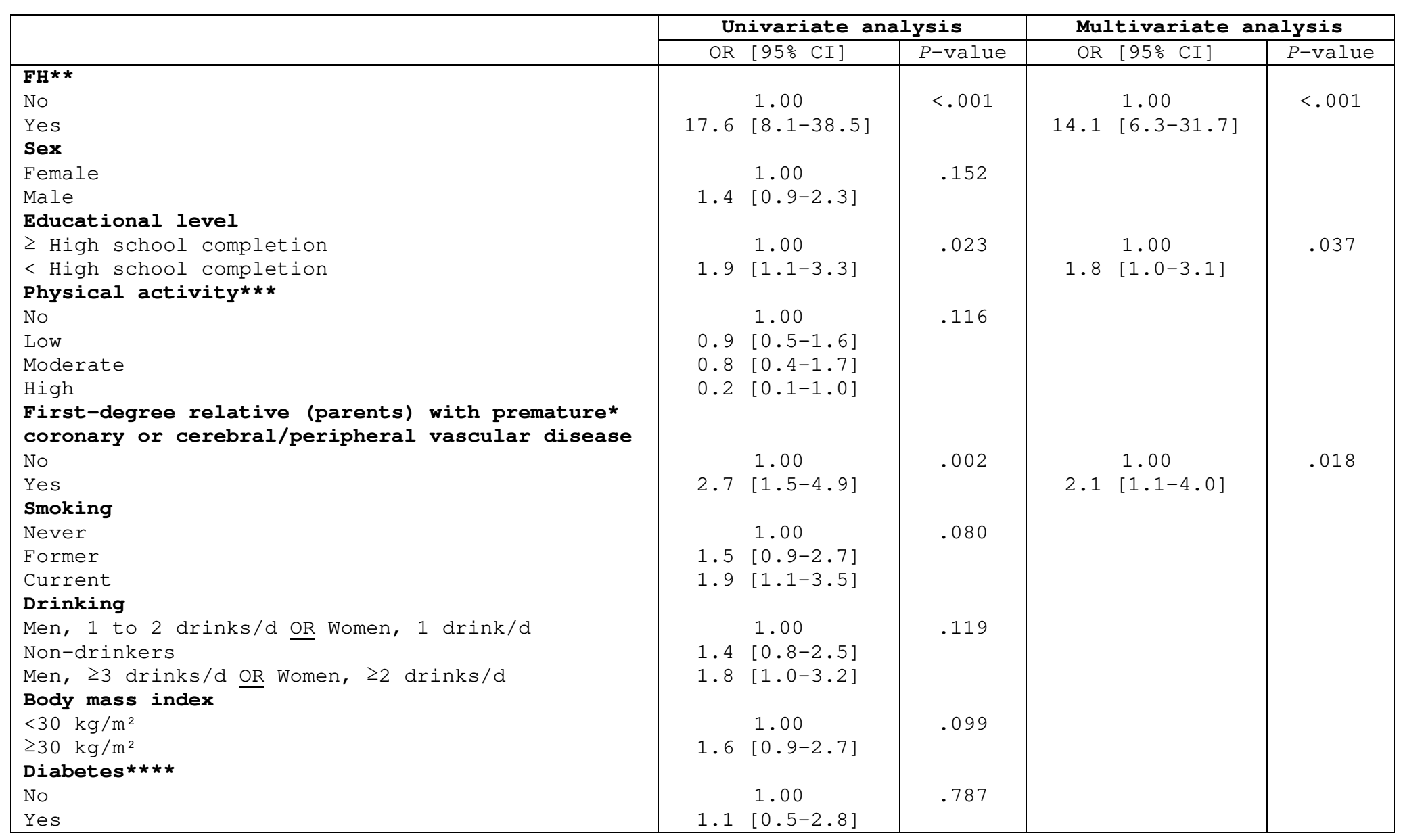




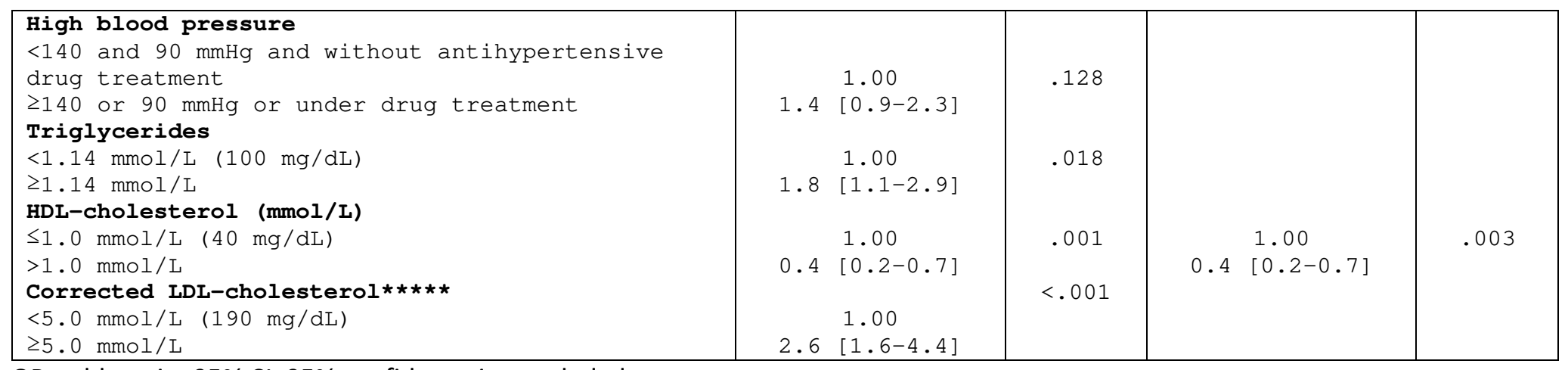

$\mathrm{OR}$, odds ratio; $95 \% \mathrm{Cl}, 95 \%$ confidence interval; d, day.

$*<55$ years in men; $<60$ years in women.

** Familial hypercholesterolemia $(\mathrm{FH})$ was considered as definite or probable for a total $>8$ or equal to 6-8 points, respectively, according to a modified version of the Dutch Lipid Clinic Network criteria: first degree relative (parents) with known premature ( $<55$ years in men; $<60$ years in women) coronary or vascular (cerebral or peripheral) disease or hyperlipidemia (1 point); subject with premature coronary artery disease (2 points); subject with premature cerebral or peripheral vascular disease (1 point); LDL-C $\geq 8.5 \mathrm{mmol} / \mathrm{L}$ (8 points), 6.5-8.4 mmol/L (5 points), $5.0-6.4 \mathrm{mmol} / \mathrm{L}$ (3 points) or $4.0-4.9 \mathrm{mmol} / \mathrm{L}$ (1 point). LDL-C was corrected (using dose- and statin- or ezetimibe-specific correction factors [14]) for subjects under statins or ezetimibe.

*** No regular physical activity versus low physical activity (such as walking or bicycling, without causing shortness of breath or sweating, almost every week) versus moderate physical activity (i.e. causing shortness of breath or sweating, during at least 20 minutes, once or twice a week) versus high physical activity (i.e. causing shortness of breath or sweating, during at least 20 minutes, three times a week or more). **** Diabetes was assessed for subjects with fasting blood glucose $\geq 7 \mathrm{mmol} / \mathrm{L}(126 \mathrm{mg} / \mathrm{dL}$ ) or under hypoglycemic drug treatment.

***** LDL-C was corrected (using dose- and statin- or ezetimibe-specific correction factors [14]) for subjects under statins or ezetimibe. 